\title{
Plasma structure within poleward-moving cusp/cleft auroral transients: EISCAT Svalbard radar observations and an explanation in terms of large local time extent of events
}

\author{
M. Lockwood ${ }^{1,2}$, I. W. McCrea ${ }^{2}$, S. E. Milan ${ }^{3}$, J. Moen ${ }^{4}$, J. C. Cerisier ${ }^{5}$, A. Thorolfsson ${ }^{5,6}$ \\ ${ }^{1}$ Department of Physics and Astronomy, Southampton University, UK \\ ${ }^{2}$ Space Science Department, Rutherford Appleton Laboratory, UK \\ ${ }^{3}$ Department of Physics and Astronomy, Leicester University, UK \\ ${ }^{4}$ Arctic Geophysics, University Courses on Svalbard, Longyearbyen, Norway \\ ${ }^{5}$ CETP, 4, avenue Neptune, F-94107 Saint-Maur, CEDEX France \\ ${ }^{6}$ Science Institute, Dunhaga 3, 107 Reykjavik, Iceland
}

Received: 21 December 1999 / Revised: 9 June 2000 / Accepted: 13 June 2000

\begin{abstract}
We report high-resolution observations of the southward-IMF cusp/cleft ionosphere made on December 16th 1998 by the EISCAT (European incoherent scatter) Svalbard radar (ESR), and compare them with observations of dayside auroral luminosity, as seen at a wavelength of $630 \mathrm{~nm}$ by a meridian scanning photometer at Ny Ålesund, and of plasma flows, as seen by the CUTLASS (co-operative UK twin location auroral sounding system) Finland HF radar. The optical data reveal a series of poleward-moving transient red-line $(630 \mathrm{~nm})$ enhancements, events that have been associated with bursts in the rate of magnetopause reconnection generating new open flux. The combined observations at this time have strong similarities to predictions of the effects of soft electron precipitation modulated by pulsed reconnection, as made by Davis and Lockwood (1996); however, the effects of rapid zonal flow in the ionosphere, caused by the magnetic curvature force on the newly opened field lines, are found to be a significant additional factor. In particular, it is shown how enhanced plasma loss rates induced by the rapid convection can explain two outstanding anomalies of the $630 \mathrm{~nm}$ transients, namely how minima in luminosity form between the poleward-moving events and how events can re-brighten as they move poleward. The observations show how cusp/cleft aurora and transient poleward-moving auroral forms appear in the ESR data and the conditions which cause enhanced $630 \mathrm{~nm}$ emission in the transients: they are an important first step in enabling the ESR to identify these features away from the winter solstice when supporting auroral observations are not available.
\end{abstract}

Key words: Ionosphere (polar ionosphere) Magnetospheric physics (magnetopause; cusp and boundary layers; solar wind-magnetosphere interactions)

Correspondence to: M. Lockwood

e-mail:m.lockwood@rl.ac.uk

\section{Introduction}

On December 16th 1998, co-ordinated observations of the cusp/cleft ionosphere were made using the EISCAT (European incoherent scatter) Svalbard radar (ESR), the EISCAT Tromsø VHF radar and a number of other instruments, including meridian scanning photometers (MSP) at Longyearbyen and Ny Alesund, the IMAGE magnetometer chain and the CUTLASS (co-operative UK twin location auroral sounding system) HF radars. An overview of the large-scale auroral and convection morphology seen on this day has been presented by McCrea et al. (this issue), who described the effects of a southward turning of the interplanetary magnetic field (IMF) and of a subsequent return to a northward orientation. Following the southward turning, the cusp/ cleft aurora migrated equatorward over the ESR and poleward-moving transient enhancements began to form. This southward motion resulted in the whole cusp/cleft region passing over the ESR, such that in a period of 30 minutes (06:30-07:00 UT) the ESR beam moved from being at the equatorward edge of the cusp/ cleft, where the transient auroral events form, to its poleward edge, where the transient events fade. In this interval, the magnetic local time of the ESR increased from about 09:15 to about 09:45. This complete view of the pre-noon cusp/cleft was achieved without moving the radar beam from the field-aligned direction, allowing us to study the field-aligned profiles of the plasma parameters in and between transient events at all phases of their evolution. Thorolfsson et al. (this issue) have described the flows in and around these polewardmoving transients and analysed them in terms of models of the effects of pulsed magnetopause reconnection. The purpose of the present paper is to analyse the plasma concentration and temperatures in and around these events and evaluate their modulation by the flows and the soft cusp/cleft particle precipitation. In particular we investigate the implications of events having large longitudinal extent. 
Poleward-moving transient events have been shown to be the normal behaviour of the cusp/cleft aurora when the IMF points southward (e.g. Sandholt et al., 1992; Fasel, 1995). Observations by the mainland EISCAT UHF and VHF radars showed that these auroral transients were co-located in space and time with transient flow bursts, revealing them to be associated with transient momentum transfer across the magnetopause (Lockwood et al., 1989a, b, 1993a, b; Moen et al., 1995, 1996a) and consequent ion-neutral heating of the ionospheric ion gas (Lockwood et al., 1993a, b, 1995a). The transient auroral events are seen to form in regions of cleft precipitation, near the equatorward edge of the cusp/cleft aurora (Moen et al., 1996b) and subsequently migrate poleward into the regions of cusp and mantle precipitation, consistent with the evolution of newly opened field lines (Sandholt et al., 1992; Lockwood et al., 1993c). The longitudinal motion of the transient auroral events also supports the idea that they are patches of newly opened flux; events in the northern hemisphere moving westward when the IMF $B_{y}$ component is positive and eastward when it is negative (e.g. Lockwood et al., 1993b): the only known explanation of this pattern of motion is the curvature ("tension") force on the newly opened field lines. The repetitive pattern of formation and motion of these events shows that patches of such field lines are produced by pulses in the reconnection rate (Lockwood et al., 1995a) and not by steady reconnection in the presence of oscillations in the $Y$ component of the magnetic field in interplanetary space (Stauning, 1994; Stauning et al., 1994, 1995) nor in the magnetosheath (Newell and Sibeck, 1993b). This pattern of event motion is also consistent with the asymmetric MLT distributions of their occurrence for $B_{y}>0$ and $B_{y}<0$ (Karlson et al., 1996), as discussed by Cowley et al. (1991a).

The area of a region of newly opened flux in the ionosphere is a direct measure of the magnitude and duration of the reconnection pulse that produced it. This is because the ionosphere is incompressible, in the sense that the magnetic field strength there is essentially constant. Lockwood et al. (1990) used the duration and east-west flow speeds of the bursts, as seen at one meridian, and deduced that at least some of the patches of newly opened flux must be extensive in longitude (up to about $2000 \mathrm{~km}$ ), meaning that they form flow channels that cover up to about 4 hours in magnetic local time. These authors also deduced that the events must have large longitudinal extents from the small magnitudes of any return flows outside the events. Pinnock et al. (1993) used HF coherent scatter radar to image these transient flow channels and showed they could indeed extend over the whole of their field of view (i.e. over more than about $900 \mathrm{~km}$ ). Milan et al. (1999) have shown that these poleward-moving flow channels are associated with poleward-moving $630 \mathrm{~nm}$ optical transients. However, the flow channels are more easily seen in the HF radar observations away from the winter solstice conditions required to detect the $630 \mathrm{~nm}$ transients and hence combined observations remain rela- tively rare. Recently, Milan et al. (2000) have shown that the flow channels are also associated with poleward-moving forms seen in global images of the UV aurora and that these were up to $2500 \mathrm{~km}$ in longitudinal extent. These UV aurora, like the $557.7 \mathrm{~nm}$ aurora studied by Lockwood et al. (1993a), appear to be coincident with the sheet of upward field-aligned current of the oppositely directed pair required to transfer the motion of the newly opened flux into the ionosphere. The east-west direction of flow in the channels seen by HF radars is controlled by the IMF $B_{y}$ (Provan et al., 1998) and their motion, as for the optical transients, is consistent with their occurrence as a function of local time (Provan and Yeoman, 1999; Provan et al., 1999). These statistical studies of the flow channels also point to large longitudinal extents. The existence of large regions of newly opened flux had been considered controversial by Newell and Sibeck (1993a) who argued that pulsed reconnection could only take place in a localised region, although Lockwood et al. (1993b) and Lockwood (1994) proposed a travelling transient reconnection pulse scenario that is not subject to the limitation proposed by Newell and Sibeck. Lockwood et al. (1993a) deduced that $630 \mathrm{~nm}$ transients could have extents comparable with those discussed above and this has been confirmed by observations using longitudinally separated ground-based instruments (Moen et al., 1995, 1996a). The significance of large events is that they occur frequently enough for pulsed reconnection to be sufficient to explain almost all of the transpolar voltage. This result is consistent with analysis of the magnetopause signatures of pulsed reconnection, provided one uses the 2-dimensional reconnection pulse model of these "flux transfer events" (Lockwood et al., 1995b). Detailed analysis of FTE signatures also strongly supports this two-dimensional model (Lockwood and Hapgood, 1998). Lockwood and Davis (1996) also show that longitudinal passes through cusp ion steps (see below) reveal that events cover considerable ranges of MLT. Hence observations by ground-based radars and cameras, by global UV imagers and by satellites (both at the magnetopause and at low altitudes) all indicate that these transient events can cover large longitudinal extents and that reconnection pulses can be, at least sometimes, the dominant contribution to the voltage across the magnetopause during southward IMF conditions.

Another predicted signature of pulsed reconnection are discontinuities in the dispersion of injected solar wind ions in the cusp region, called "cusp ion steps" (Cowley et al., 1991b; Lockwood and Smith, 1992, 1994; Escoubet et al., 1992; Lockwood and Davis, 1996). Modelling of the effects of pulsed magnetopause reconnection has been shown to reproduce the observed simultaneous steps in both downgoing and upgoing ions in the cusp at middle altitudes - clearly demonstrating that these events are caused by pulsed reconnection and not by pulsed plasma transfer across the magnetopause (Lockwood et al., 1998). Cusp ion steps have been seen in association with poleward-moving patches of elevated electron temperature (detected by incoherent scatter 
radar) by Lockwood et al. (1993c), and with polewardmoving cusp/cleft auroral transients by Farrugia et al. (1998). Pinnock et al. (1995) found the poleward-moving flow channels (detected by HF radar) were in association with a seemingly different "sawtooth" signature in the cusp ions. However, Lockwood and Davis (1996) showed that this sawtooth signature was, in fact, the same phenomenon as the cusp ion steps seen by Lockwood et al. (1993c) - the differences arising purely from the longitudinal nature of the satellite pass studied by Pinnock et al.

To summarise the above discussion, the theory of the effects of pulsed magnetopause reconnection predicts poleward-moving flow bursts/channels, poleward-moving optical transients and cusp ion steps. These have indeed all been detected in association with each other by Yeoman et al. (1997).

Transient reconnection signatures in the ionosphere were first revealed by optical observations, which remain a primary means of identification. The problem with this is that the optical observations of the cusp/cleft are only possible for the extreme dipole tilt conditions at winter solstice and there are reasons to expect the behaviour to be different at other times of the year when the Earth's magnetic dipole tilt is different (Newell and Meng, 1989; Lockwood and Moen, 1999). This makes it vital that the signatures of the cusp/cleft and its transient variations be identified in ESR radar data, such that we can identify and study these events at all times of the year. Lockwood et al. (1993a, b, c) detected elevated electron and ion temperatures in association with the polewardmoving transient flows and cusp/cleft auroral events. In addition, Lockwood and Carlson (1992) reported poleward-moving F-region plasma concentration enhancements in the cusp/cleft region that they also associated with pulsed magnetopause reconnection. They interpreted the concentration enhancements as being due to changes in the pattern of flow modulating the entry into the polar cap of EUV-produced sub-auroral plasma. However, Rodger et al. (1994) pointed out that plasma production by soft particle precipitation and plasma loss by enhanced electric fields and reaction rates may also be significant factors in introducing structure into the plasma concentrations on the timescales for flux tubes to enter the polar cap.

All of the above measurements of ionospheric plasma parameters within the cusp/cleft transients were made using the mainland EISCAT radars which can only view the cusp using low-elevation beams to the north. As a consequence, latitudinal and altitudinal variations were convolved along the radar beam in these observations. The new EISCAT Svalbard radar (ESR) allows us to view these events along the field line for the first time (see review by McCrea and Lockwood, 1997). Initial observations by the ESR (Sedgemore-Schulthess et al., 1999) show the sort of structure in the cusp region that was predicted for pulsed reconnection by Davis and Lockwood (1996). However, these predictions were made using a number of simplifying assumptions. One of our main aims in carrying out the December 1998 campaign was to test these assumptions and the result- ing predictions by looking at the association of signatures in ESR radar data with the optical observations of cusp/cleft transients.

\section{Instrumentation}

On December 16th 1998, the EISCAT Svalbard radar was operated with the beam fixed in the field-aligned direction (azimuth $180.6^{\circ}$, elevation $81.6^{\circ}$ ) and using the GUP3 modulation scheme. This experiment combines both plain and phase-coded pulses to make measurements over a continuous range of altitudes from 90 to $1000 \mathrm{~km}$. A technique known as "moving target clutter cancellation" is used to remove unwanted echoes which arise from the surrounding mountains on Svalbard up to a range of about $150 \mathrm{~km}$, so that only the ionospheric contribution remains. By using the Finnish GUISDAP analysis programme, the ESR data have been analysed in such a way that the altitude resolution at any given height corresponds closely to the ionospheric scale height in that region. The data shown here have been analysed with no post-integration and were pre-integrated over 10-second intervals before recording.

Simultaneous observations were made by meridian scanning photometers (MSP) at Ny Ålesund. These instruments detect the red- and green-line auroral emissions from excited atomic oxygen (at wavelengths of $630.0 \mathrm{~nm}$ and $557.7 \mathrm{~nm}$ ) which mainly arise from E- and F-region altitudes, respectively. The instruments scan in the geomagnetic meridian approximately once every 20 seconds, from elevations of $50^{\circ} \mathrm{N}$ to $50^{\circ} \mathrm{S}$.

The CUTLASS bistatic HF radar was also operated during the interval studied here. Both the Finland and Iceland radars operated in a mode with a three-minute cycle time. In this paper, we use data from the CUTLASS Finland radar, located at Hankasalmi $\left(62.3^{\circ} \mathrm{N}, 26.6^{\circ} \mathrm{E}\right)$, taken during scans of 14 beam azimuths that last for 1 minute. A total of 75 range gates were sampled along each beam direction, giving range gates $45 \mathrm{~km}$ long, covering ranges of 180 $3555 \mathrm{~km}$. Because of uncertainties in the HF ray path from the transmit/receive site to the scattering volume, we do not know precisely the relationship of the ground range to the slant path range: as a result, the location of the point of scatter is known to within about one range gate (i.e. $\pm 45 \mathrm{~km}$ ). Furthermore, the altitude of the scattering volumes is not known and the inclination of the ESR field line means that the slant range from Hankasalmi to the ESR beam depends on the altitude. These factors mean that precise identification of the CUTLASS scattering volume around the ESR beam is not possible.

McCrea et al. (this issue) have studied the dependence of cusp/cleft region on the IMF orientation on 16th December 1998. In particular, they observed an equatorward motion of the cusp/cleft, as defined by dominant $630 \mathrm{~nm}$ emission seen by the MSP and by enhanced electron temperature seen by the EISCAT VHF radar. This passed over the ESR radar beam at 
06:30-07:00 UT (for which the magnetic local times, MLT, were approximately 09:15-19:45), following a southward turning of the IMF seen by ACE at the L1 point at 05:15-05:25 and by WIND close to the magnetopause near 06:20. In this paper we study this traversal of the cusp/cleft in greater detail.

\section{Observations}

\subsection{Optical observations}

Fig. 1 shows the intensity of $630 \mathrm{~nm}$ light, as seen by the MSP at Ny Allesund, $130 \mathrm{~km}$ north of the ESR, colourcoded as a function of time and zenith angle. Data are shown for 06:30-07:15 UT. These red-line emissions emanate from a range of altitudes. The approximate location of the ESR is shown by the horizontal white line, based on assumed peak emission altitude of $300 \mathrm{~km}$. McCrea et al. (this issue) present observations of both the red-line $(630 \mathrm{~nm})$ and green-line $(557.7 \mathrm{~nm})$ emissions which show that the ratio of the two intensities $\mathrm{I}_{630} / \mathrm{I}_{557.7}$ is high (2-10) wherever $\mathrm{I}_{630}$ is high $(>5 \mathrm{kR}$ ), indicating that the $630 \mathrm{~nm}$ emissions are due to soft "cusp/cleft" precipitation of magnetosheath plasma.

In addition to showing the passage of the cusp/cleft aurora from north to south of the ESR, Fig. 1 reveals a great deal of structure and, in particular, the polewardmoving red-line transients that are typical of southwardIMF conditions (Sandholt et al., 1992; Fasel, 1995). Events are labelled $a-g$ by the time at which they crossed the approximate location of the ESR beam. Note that event $a$ did not fully brighten until it was poleward of the ESR and, in this case, the duration given is an extrapolation back in time and latitude to the ESR location. Many of the events were brightest early and late in their lifetime. Events migrate eastward (Thorolfsson et al., this issue), consistent with the negative IMF $B_{y}$ component at this time. Because the MSP only samples one meridian, this variation in brightness could be caused by longitudinal structure and eastward motion of the events; however all-sky images (Thorolfsson et al., this issue) do not show any evidence for such structure. The effect is also consistent with the rebrightening of the entire poleward-moving event, as was noted in many white light all-sky images by Fasel et al. (1992). Event $a$ was seen by the ESR before its main brightening, event $b$ was seen just after its initial brightening, events $c$ and $d$ were seen just before they re-brightened and events $e, f$ and $g$ were seen in the middle of their second brightening. After event $g$, luminosities near the ESR faded and all subsequent brightenings remained equatorward of the ESR location. McCrea et al. (this issue) use a number of diagnostics to identify the region seen by the ESR after event $g$ as the polar cap.

\subsection{ESR observations}

The three panels of Fig. 2 show (from top to bottom) the electron concentration, $N_{\mathrm{e}}$, electron temperature, $T_{\mathrm{e}}$, and the field-aligned ion temperature, $T_{\|}$, as measured by the ESR during the interval from 06:33 to 07:03. These are 10-second integrations of the data and are plotted as a function of altitude and time. Figure 2 also

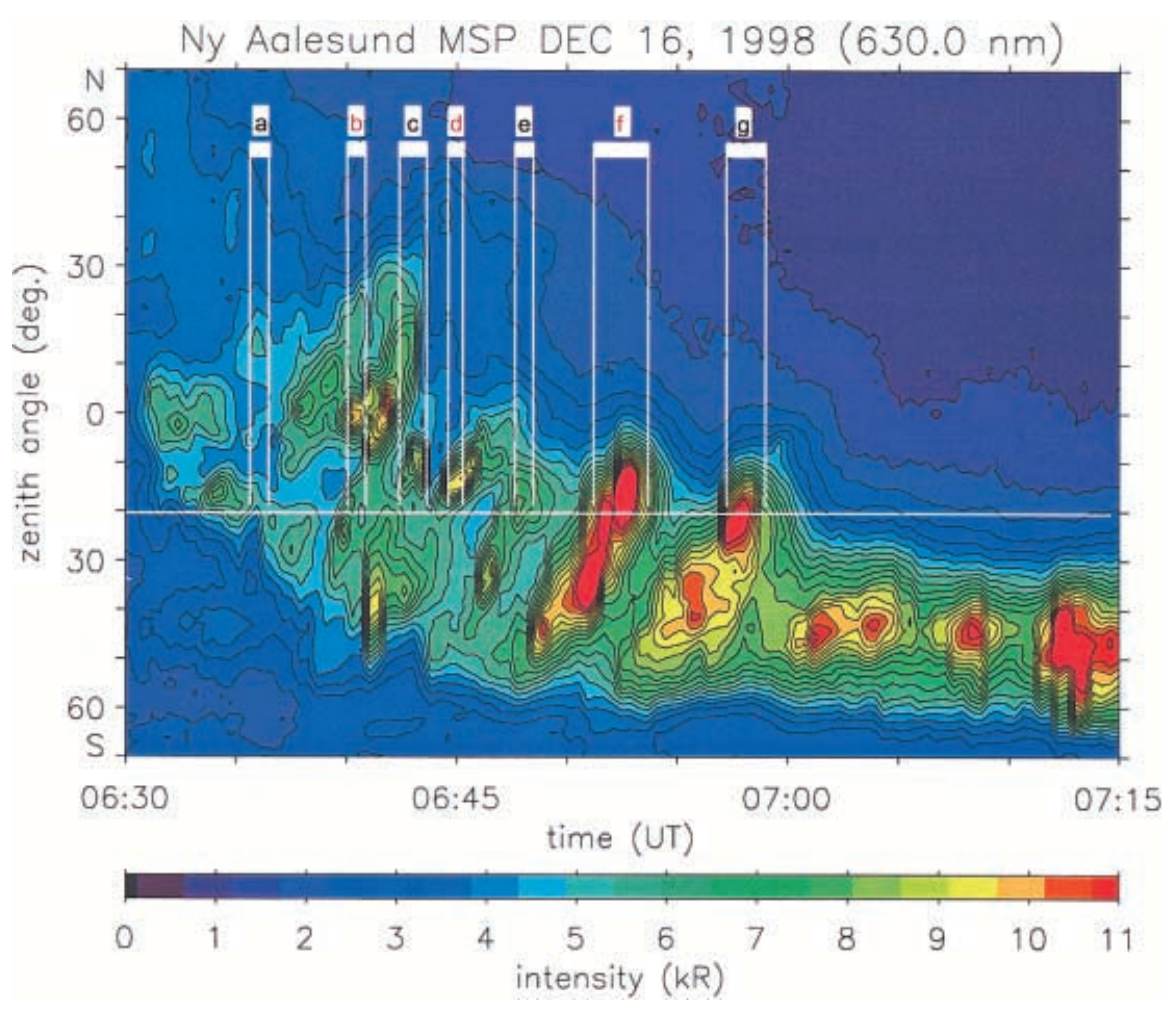

Fig. 1. Integral line-of-sight intensity of $630 \mathrm{~nm}$ emissions, as seen by the $630 \mathrm{~nm}$ meridian-scanning photometer at Ny Ålesund, colour-coded as a function of zenith angle and time. The horizontal line shows the zenith angle of the ESR radar beam for an assumed emission altitude of $300 \mathrm{~km}$. The passages of poleward-moving events through this approximate location of the ESR beam are marked as events $a-g$ 


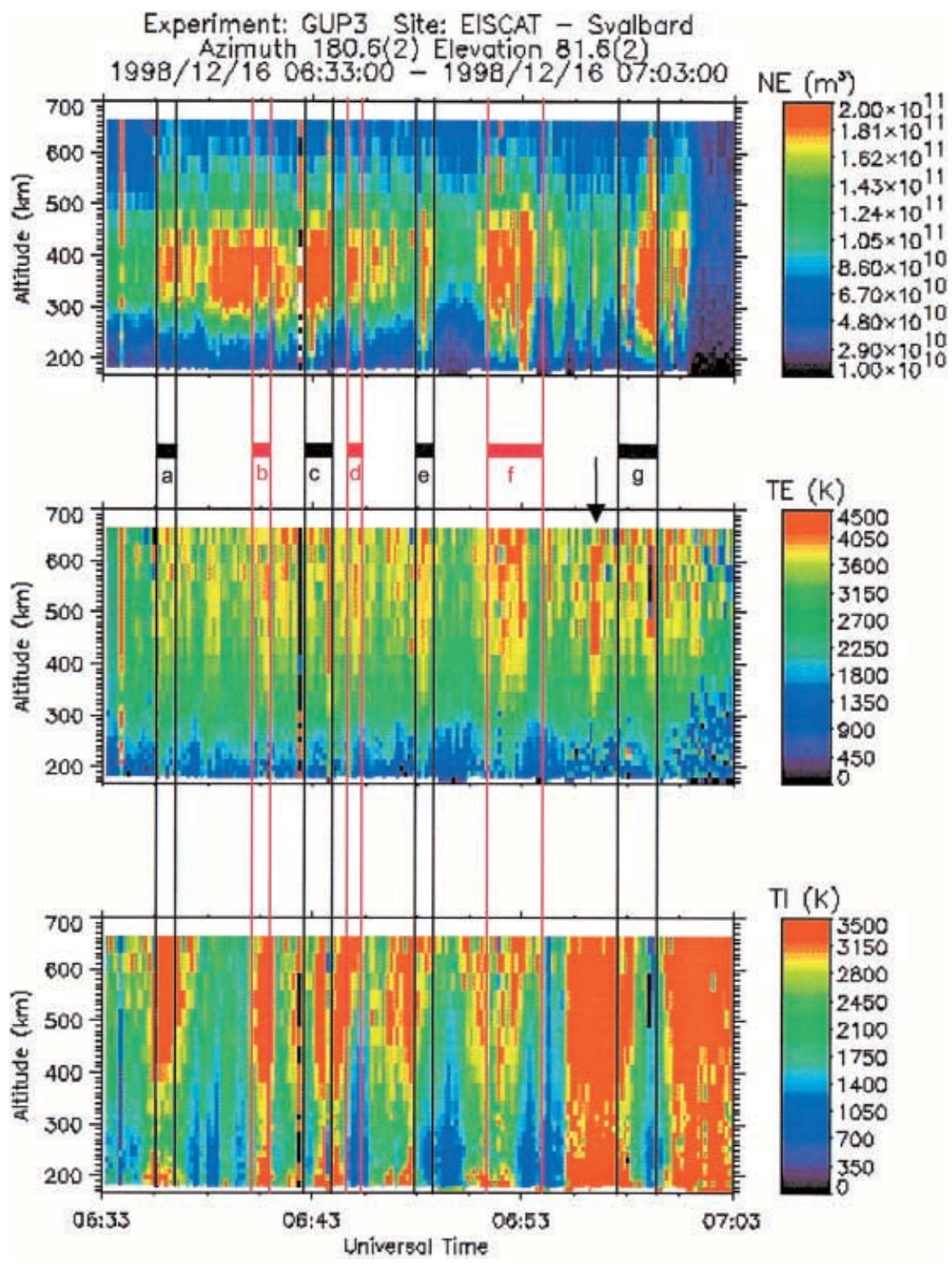

Fig. 2. Details of the ESR data between 06:33 and 07:03 UT, when the southwardIMF cusp/cleft passed over the radar. (From top to bottom) the electron concentration, $N_{\mathrm{e}}$, electron temperature, $T_{\mathrm{e}}$, and the fieldparallel ion temperature, $T_{\|}$, as function of height and time and analysed at 10 -second resolution. The vertical lines mark the passage of poleward-moving $630 \mathrm{~nm}$ transients over the approximate location of the ESR beam, as shown in Fig. 1. Lines bounding events are coloured alternately black and red and events are labelled $a-g$ as in Fig. 1 shows the intervals $a-g$ defined in Fig. 1 as when the poleward-moving events passed over the approximate ESR location.

In the electron concentration $N_{\mathrm{e}}$ data, events $a-e$ produced no clear signature, and although there were enhancements at F-region altitudes coincident with $d$ and $e$, there were also enhancements between $d$ and $e$ that were not accompanied by $630 \mathrm{~nm}$ enhancements (see Fig. 1). Events $f$ and $g$, on the other hand, were accompanied by clear enhancements in $N_{\mathrm{e}}$. After event $g$ had faded, values of $N_{\mathrm{e}}$ were very low as the ESR entered the polar cap. Enhancements in $N_{\mathrm{e}}$ that extend down to the lowest altitudes were seen at the start of events $c$ and $e$ and at the end of event $f$. These always correspond to a time when the field-parallel ion temperatures, $T_{\|}$, fell considerably revealing a change in the flow and implying the presence of a field-aligned current.

The electron temperature is enhanced throughout the cusp/cleft crossing. There were enhancements associated with all events after event $a$. However we also note that there were also enhancements that were not associated with a $630 \mathrm{~nm}$ transient. The clearest of these occurred between events $f$ and $g$ and is marked with a vertical arrow in Fig. 2. Figures 3 and 4 show altitude profiles of, respectively, the electron concentration and electron temperature. These are one-minute post-integrations of the data for periods when the 10-second data showed little variation and were representative of 4 different sets of conditions. The blue profiles in both figures are for 06:16-17 UT, when the ESR was at sub-auroral latitudes, the MSP and the EISCAT VHF radar showing the cusp/cleft region to be poleward of the ESR (McCrea et al., this issue). The yellow profiles are for 06:52-53, when the ESR was within the cusp/cleft region and within the poleward-moving auroral transient $f$ shown in Fig. 1. The green profiles are for 06:5657 when the ESR was within the cusp/cleft region but between cusp/cleft transients $f$ and $g$ (the time marked with the arrow in Fig. 2). The red profiles are 


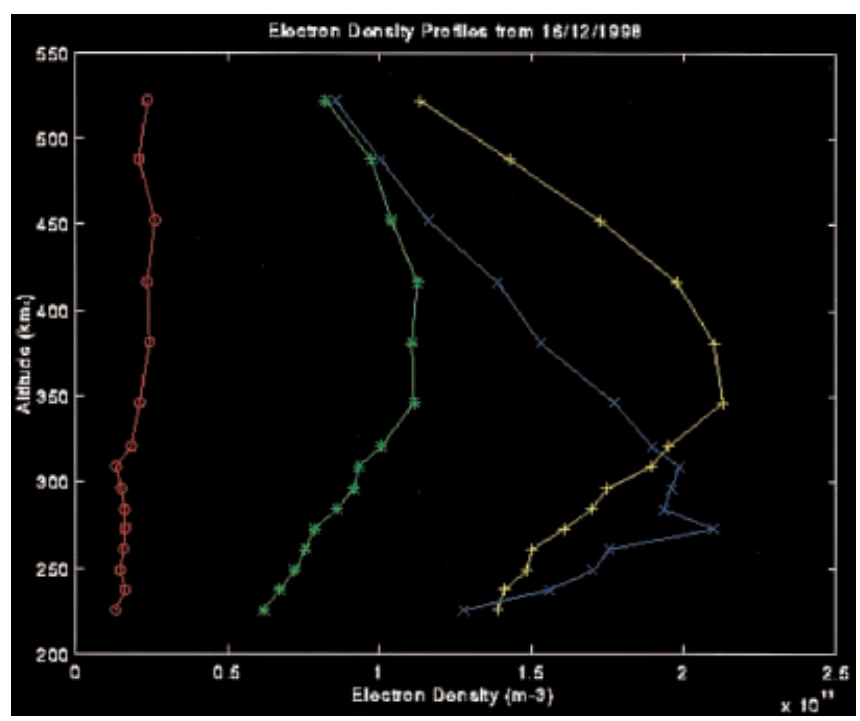

Fig. 3. Altitude profiles of electron concentration, $N_{\mathrm{e}}$, for four oneminute integrations of the ESR data. Blue $(x)$ : 06:16-17 UT, when the ESR was at sub-auroral latitudes. Yellow $(+)$ : 06:52-53, when the ESR was within the cusp/cleft transient $f$. Green $(*)$ : 06:56-57 when the ESR was between cusp/cleft transients $f$ and $g$ (the time marked with the arrow in Fig. 2). Red (o): 07:15-16 UT when the ESR was within the polar cap

for 07:15-16 UT when the ESR was within the polar cap and poleward of the cusp/cleft.

A number of features are apparent in Figs. 3 and 4. Firstly, plasma concentrations in the polar cap are extremely low, with peak values at altitudes above $450 \mathrm{~km}$. These low values introduce noise into the temperature estimates, but the electron temperatures seen within the polar cap are similar to, but slightly lower than, those seen at sub-auroral latitudes. The peak electron concentration at sub-auroral latitudes is as high as within the $630 \mathrm{~nm}$ transient event, but the altitude of the peak is $270 \mathrm{~km}$, whereas both profiles $N_{\mathrm{e}}$ in the cusp/cleft region peak at altitudes of about $350-400 \mathrm{~km}$. Both of the cusp/ cleft profiles, inside and outside the $630 \mathrm{~nm}$ transient, show elevated electron temperatures but the major difference between the two is that within the $630 \mathrm{~nm}$ transient the plasma concentration is much higher.

The behaviour of the field-parallel ion temperatures $T_{\|}$(bottom panel Fig. 2) varies as the ESR moves from the equatorward to poleward edge of the cusp/cleft. For events $a, b$ and $c$ there was a transient rise within each $630 \mathrm{~nm}$ event. For events $d, e$ and $f$ there was a transient rise that commenced before each event but then decreased back to background values within the event, with $T_{\|}$remaining low after the event has moved poleward of the ESR. For event $g$, the radar was in a region of consistently high $T_{\|}$which dropped in the middle of the event and did not recover until the event had passed.

The ion temperature can be determined, to a good degree of accuracy, from the largest two terms in the ion thermal balance equation (Lockwood et al., 1993d; McCrea et al., 1991, 1993; Davies et al., 1997, 1999) such that the field-parallel ion temperature is:

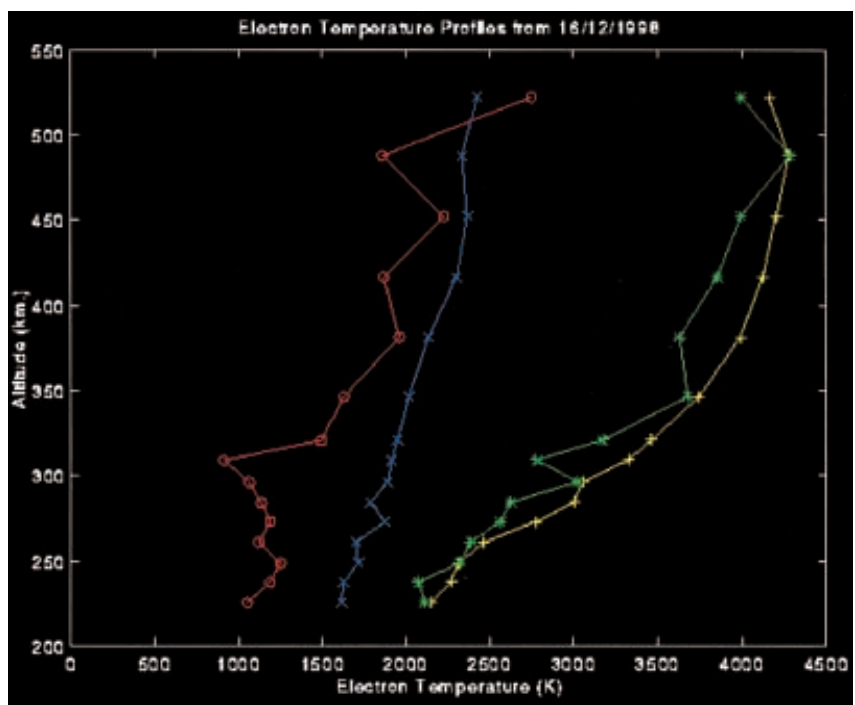

Fig. 4. Same as Fig. 3 for the electron temperature, $T_{\mathrm{e}}$

$T_{\|}=T_{n}+\left(\beta_{\|} m_{n} / 2 k\right)|\underline{V}-\underline{U}|^{2}$

where $T_{n}$ is the temperature and $m_{n}$ is the mean mass of the neutral gas atoms/molecules; $\beta_{\|}$is the temperature partition coefficient; $k$ is Boltzmann's constant; $V$ and $U$ are the ion and neutral gas velocity vectors, respectively. The coefficient $\beta_{\|}$has a minimum value of zero (the "relaxation model" of ion-neutral collisions which would be valid for charge exchange with no momentum exchange) and a maximum value of $2 / 3$ (for isotropic scattering). A lower $\beta_{\|}$corresponds to a higher temperature anisotropy. McCrea et al. (1993) found that $\beta_{\text {}}$ was about $1 / 3$ near $300 \mathrm{~km}$ but rose to values nearer $2 /$ 3 at greater altitudes because the isotropising effects of ion-ion collisions become as important as the anisotropic heating effect of ion-neutral collisions. At the highest altitudes, heat conduction from the electron to the ion gas may become important as electron temperatures are generally higher.

The ion temperatures $T_{\|}$observed at altitudes above about $350 \mathrm{~km}$ persistently returned to a minimum near $1500 \mathrm{~K}$. Only one or two 10 -second integrations in the 30 minutes gave values lower than this and they were subject to unusually large measurement errors. Equation (1) predicts that $T$ will fall to a persistent minimum of $T_{n}$ whenever $V=U$. Thus we can estimate the altitudeindependent exospheric temperature above $350 \mathrm{~km}$ to be $T_{n} \approx 1500 \mathrm{~K}$. The $T_{\|}$observed within the ion heating events shows a clear altitude profile, with minimum values at about $275 \mathrm{~km}$. Above this height, $T_{\|}$rises with altitude because $\beta_{\|}$rises as ion-ion collisions become more important. Below $275 \mathrm{~km}$, the ratio of the ionneutral collision frequency and the gyrofrequency becomes very large and this will cause the $\beta_{\|}$to rise (Lathuillere et al., 1991) and the mean neutral mass $m_{n}$ rises with decreasing altitude, giving higher ion temperatures (Schunk and Sojka, 1982). These effects can be seen in the temperature profiles modelled for ion-neutral frictional heating events by Jenkins et al. (1997): in these 
studies, the parallel ion temperature is only slightly smaller than the perpendicular value at a height of $600 \mathrm{~km}$, showing that the $\mathrm{O}^{+}$ion gas there is almost isotropic and $\beta_{\|}$is approaching its upper limit of $2 / 3$. In the following section, we look at the $T_{\|}$values at altitudes above $600 \mathrm{~km}$ and assume an isotropic ion gas with $\beta_{\|}=2 / 3$.

\subsection{CUTLASS Finland radar observations}

Figures 5 and 6 show the convection vectors deduced from the CUTLASS Finland radar. The vectors were determined by a beam-swinging technique, as described by Ruohoniemi et al. (1989). This technique assumes that the zonal component of the plasma drift is constant across the field-of-view of the radar. The line-of-sight velocities measured by the radar are a convolution of the zonal and meridional components of the plasma drift. The zonal component of the drift reveals itself as a cosine dependence in the line-of-sight velocities as the radar sweeps in azimuth. The line-of-sight velocities within the field-of-view are binned in $2^{\circ}$ bands of magnetic latitude, and the beam perpendicular component of the plasma drift determined by a least-squares fit to the cosine of the angle each radar beam makes to the local L-shell. The individual vectors in this latitudinal band are then constructed from this fitted perpendicular component and the measured beam parallel component in each radar cell. Zero Doppler shift echoes, nearly all of which arise from ground scatter, have been eliminated. Plots are shown for each of the azimuth scans which

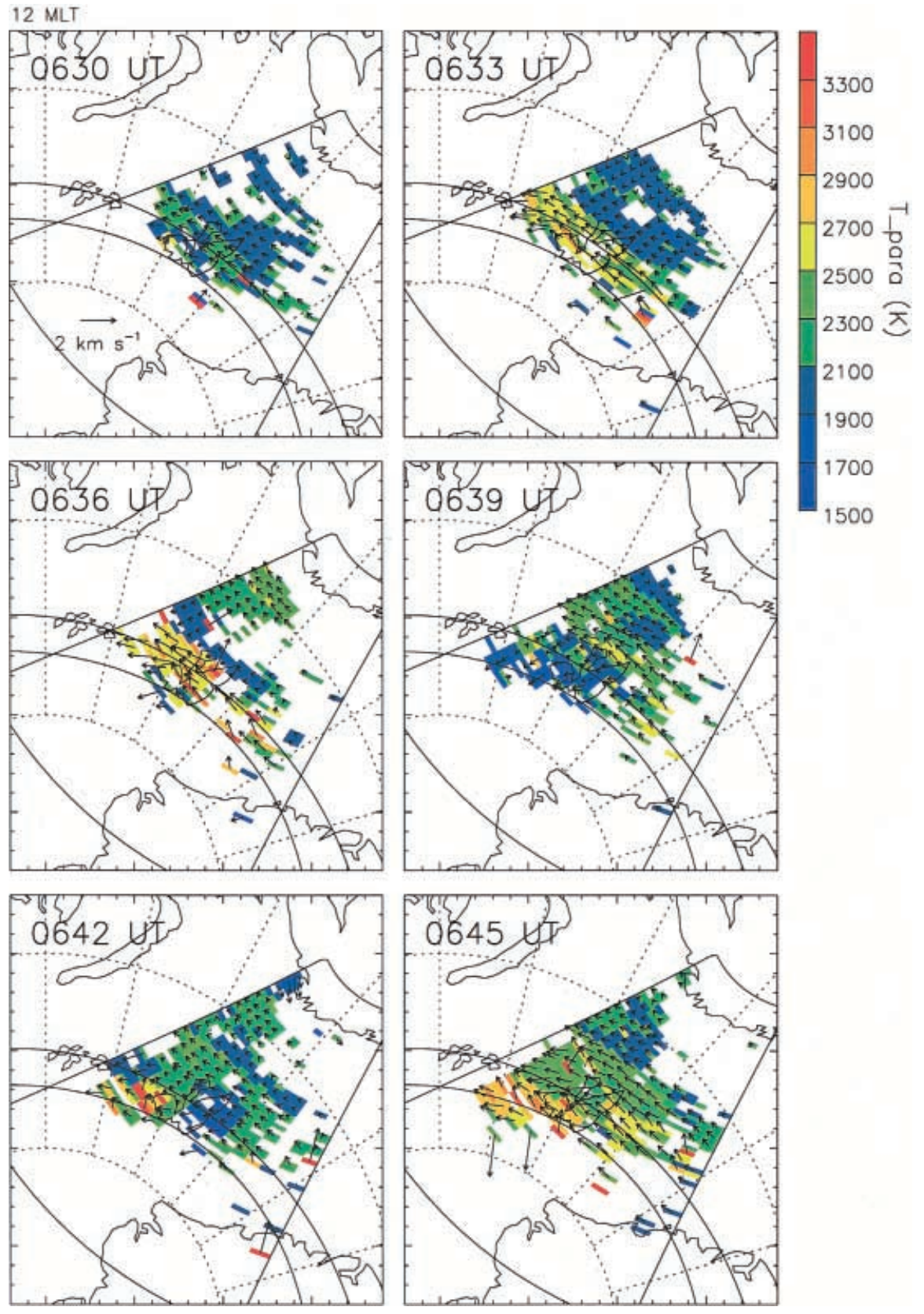

Fig. 5. Fan plots of the convection flow vectors deduced from line-of-sight velocities observed by the CUTLASS Finland radar. The colour scale gives the inferred fieldparallel ion temperature for a neutral wind speed of $U=1 \mathrm{~km} \mathrm{~s}^{-1}$ in the direction of magnetic north, a neutral temperature $T_{n}=1500 \mathrm{~K}$ and an isotropy factor $\beta_{\|}=$ $2 / 3$. In each panel, 12 MLT is the vertical dotted line and dotted circles are at 75 and $85^{\circ}$ magnetic latitude: the two solid lines show the same reference statistical auroral oval location in each case. Plots are for scans every 3 minutes with start times between 06:30 and 06:45. The time label on each plot refers to the start of the oneminute interval taken to build up each scan. Events can be related to events $a-d$ seen in the ESR and photometer data. Event $a$ is seen forming at 06:33 as a channel of higher $T_{\|}$around the equatorward edge of the statistical oval, by $06: 36$ it has intensified and by $06: 39$ is a region of lower $T_{\|}$mainly to the north-east of Svalbard. Event $b$ is seen as a smaller channel of weakly enhanced $T_{\|}$forming equatorward of event $a$ at 06:39 and as a patch of low $T_{\|}$over Svalbard at 06:42 (note that at this time, $T_{\|}$ is enhanced in a region of equatorward flow to the east of event $b$ ). Event $c$, with a younger event $d$ equatorward of it, are seen as channels of, respectively, high and moderate $T_{\| \mid}$at $06: 45$ 

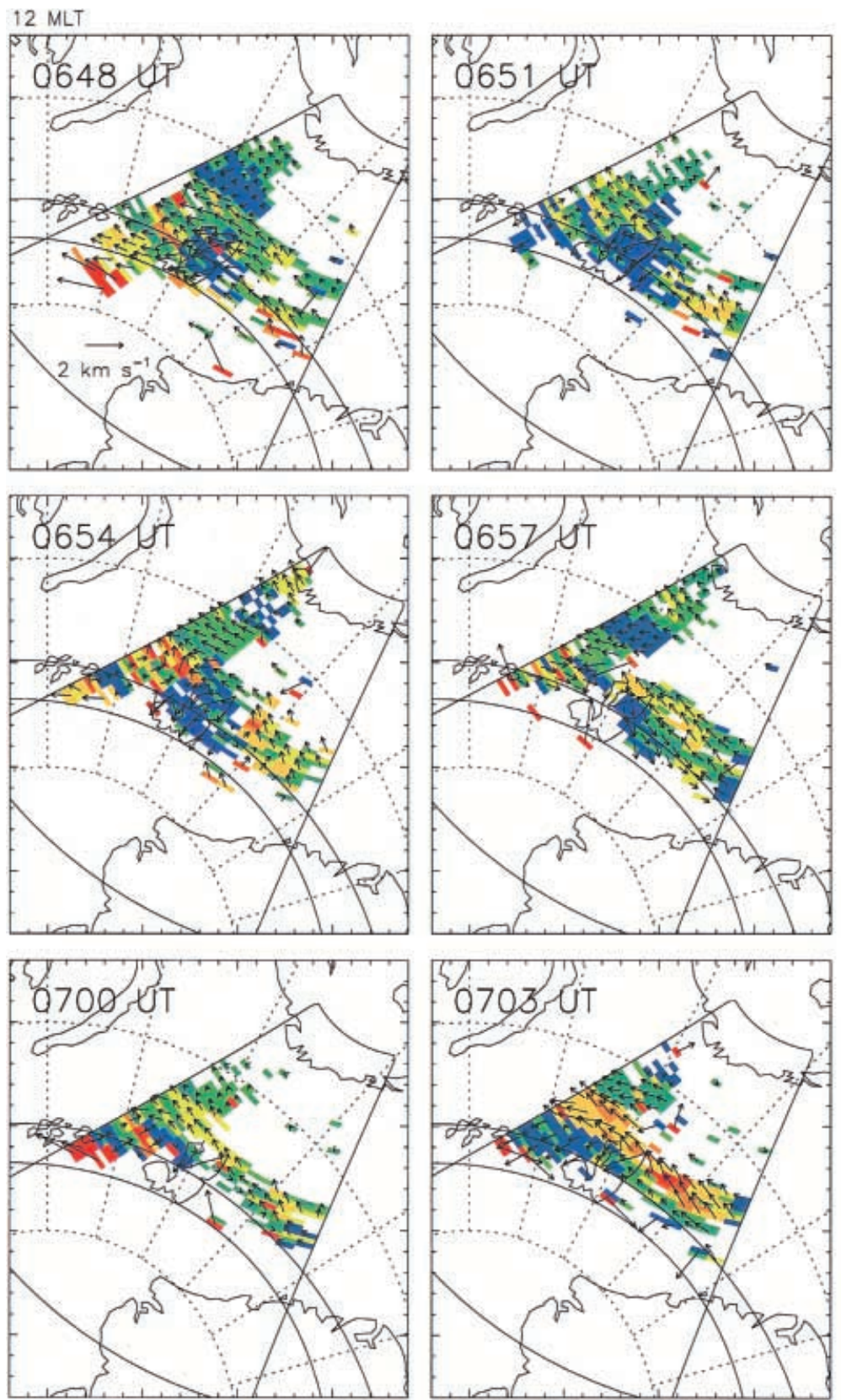

3300

3100

2900

$2700 \frac{1}{0}$

2500 긍

$2300 \widehat{\nwarrow}$

2100

1900

1700

1500
Fig. 6. Same as Fig. 5 for scan start times between 06:48 and 07:03. Event $e$ is a region of decaying $T_{\|}$over Svalbard at 06:38 (with higher $T_{\|}$to the east), with event $f$ forming as a channel of growing $T_{\|}$equatorward of it (and considerably equatorward of the statistical oval). Event $f$ has evolved into a region of low $T_{\| \mid}$over Svalbard by 06:54 (note that at this time, high $T_{\|}$is seen to both the west and east of this event, in regions of equatorward flow and that event $g$ is forming equatorward of it). Event $h$ is seen as a channel of high $T_{\|}$forming equatorward of the decaying event $g$ at 06:57 and, similarly, an event $i$ is seen forming equatorward of $h$ at 07:00. By 07:03, event $h$ is a region of low $T_{\|}$almost entirely to the east of Svalbard and event $i$ is a channel of high $T_{\|}$equatorward of it. Event $i$, and all subsequent events, move to the east of Svalbard before migrating poleward are $3 \mathrm{~min}$ apart and take $1 \mathrm{~min}$ to complete. The time label on each plot refers to the start of the one-minute scan. Note that this vector field derived is consistent with all the observed line-of-sight velocities; however, the assumptions made in the derivation mean that the vectors presented are not a unique solution.

We here take an average of the flow speed and direction around the ESR deduced from the CUTLASS Finland radar at the times when there was no detectable ion heating (when $T_{\|} \approx T_{n} \approx 1500 \mathrm{~K}$ ). This averaging is required because we cannot precisely identify the scattering volume closest to the ESR. We find that the ion flow vectors at these times was of the order of $1 \mathrm{~km} \mathrm{~s}^{-1}$ in magnitude and pointed approximately northward. Equation (1) predicts that $T_{\|}$will fall to a persistent minimum of $T_{n}$ whenever $V=U$ and thus we can use the observed $V$ vector at such times as an estimate of the neutral wind $U$. The colour-coded pixels in Figs. 5 and 6 are the field-parallel ion temperatures $T_{\|}$at altitudes above about $600 \mathrm{~km}$, deduced from Eq. (1) using $T_{n}$ of $1500 \mathrm{~K}, \beta_{\|}$of $2 / 3, m_{n}$ of $16 \mathrm{AMU}$ (O atoms), and $U$ of $1 \mathrm{~km} \mathrm{~s}^{-1}$ in the magnetic northward direction. The plots show that values of $T_{\|}$up to $3500 \mathrm{~K}$ are deduced, comparable with the range of values seen by the ESR (Fig. 2). However, when co-incident data from CUTLASS and the ESR are available within one of the transient heating events, the temperatures deduced from Eq. (1) and the CUTLASS data are typically 200-400 K lower than seen by the ESR. These smaller differences may well be due to heat conduction from the electron 
gas as the ESR detects higher electron temperatures and Eq. (1) neglects such terms.

At 06:30-31 (Fig. 5), flows and ion temperatures were relatively low for the whole of the region from where the CUTLASS radar detected backscatter from the ionosphere. At 06:33-34 consistently enhanced ion temperatures $(>2500 \mathrm{~K})$ were seen at higher latitudes due to the channel of eastward flow that had appeared. This eastward flow is consistent with the negative IMF $B_{y}$ at this time and with the flows deduced from the EISCAT VHF radar (McCrea et al., this issue). The inferred field-parallel ion temperatures are consistent with those seen by the ESR. At 06:36-37 the flows were yet further enhanced and the inferred temperatures approach those seen by the ESR within event $a$. An additional difference may have arisen from heat conduction from the electron gas because the ESR had moved into the cusp/cleft precipitation region and electron temperatures rose from about $3000 \mathrm{~K}$ to more than $3600 \mathrm{~K}$. By 06:39-41 flows and inferred temperatures had fallen again, as in the ESR data. Thus we can firmly identify the transient flow channel seen in the CUTLASS data with the transient temperature rise seen by the ESR which subsequently evolved into the poleward-moving $630 \mathrm{~nm}$ transient $a$ seen by the MSP (Fig. 1). Events $b, c$ and $d$ cannot easily be identified in the CUTLASS data because all three took place within $5 \mathrm{~min}$ and the CUTLASS scans are $3 \mathrm{~min}$ apart.

As discussed in section 3.1, $630 \mathrm{~nm}$ transients $a-d$ were seen at the ESR early in the development, whereas events $e-g$ were at the ESR later in their development. In the next section, we will discuss why we expect the ion temperature within and around events to vary considerably as the events evolve and thus why events $e, f$ and $g$ in Fig. 6 may appear considerably different to event $a$ that we were able to identify in Fig. 5. At 06:48-49, the ESR was within event $e$ and observing low ion temperatures which are reflected in the low inferred temperatures from the CUTLASS radar in a patch around the ESR (within this patch, the flow was poleward and at about $1 \mathrm{~km}$ $\mathrm{s}^{-1}$ ). At 06:51-52 temperatures were still low at and around the ESR, but enhanced values were seen entering the CUTLASS field of view from the west. We can identify these eastward flows as event $f$ early in its lifetime (see Sect. 4.5) and by 06:54-55, when event $f$ had moved to be over the ESR it, like event $e$ before it, appeared as a patch of poleward flow and low ion temperature. At 06:57-58, the ESR saw high ion temperatures which in section 4.5 we identify as event $g$ early in its lifetime. By 07:00-01 there was no CUTLASS backscatter from near the ESR. However a flow channel was forming equatorward of it. This was fully developed by 07:03. At this time, enhancement of the $630 \mathrm{~nm}$ aurora was seen equatorward of the ESR (Fig. 1) but this did not migrate poleward at the meridian scanned by the MSP. Comparison of the latitudes of the flow channel events seen at 06:33-34 and at 07:03-04 reveals the equatorward expansion of the cusp/cleft evident in Fig. 1.

\section{Discussion}

The MSP data presented here show 7 events in a 30minute interval, giving a mean repeat period of about 4 minutes. This is mid-way between the mode value and the mean value of the distribution of repeat periods for poleward-moving cusp/cleft auroral transients, as found by Fasel (1995). Inspection of Fig. 1, shows that some events are as little as $1.5 \mathrm{~min}$ apart. As discussed in section 1, the motion and occurrence of these events have been well explained in terms of pulsed magnetopause reconnection. The repeat periods found here are also consistent with those of FTEs at the magnetopause (Lockwood and Wild, 1993) and deduced from cusp ion steps (Lockwood et al., 1998), events which are also well explained in terms of the effects of reconnection pulses (see reviews by Lockwood and Hapgood, 1998 and Lockwood and Davis, 1996; respectively). The ESR data presented here give us our first opportunity to study the field-parallel profiles of plasma parameters in and around these events and, in particular, to compare with the predictions made for the ESR by Davis and Lockwood (1996 - hereafter referred to as D\&L) for periods when the magnetopause reconnection rate is pulsed.

\subsection{Comparisons of the ESR data with predictions}

The predictions of the radar and MSP signatures by D\&L were based on the assumption that the IMF $B_{y}$ (and associated east-west flows and ion heating) was negligibly small. Davis and Lockwood modelled poleward-moving $630 \mathrm{~nm}$ events using the same formulation of the effects of pulsed reconnection as used by Lockwood and Davis (1996) successfully to model both meridional and longitudinal passes of low-altitude spacecraft through cusp ion steps and also used by Lockwood et al. (1998) to model simultaneous steps in the up- and down-going ions in the mid-altitude cusp. The concepts of this model were also used by Onsager et al. (1993), Lockwood (1997) and Federov et al. (1999) to model steady-state cusp ion distribution functions at low, middle and high altitudes, respectively, and by Lockwood and Hapgood (1998) to model the ions in a magnetopause FTE.

The variation in the altitude profiles of $N_{\mathrm{e}}$ and $T_{\mathrm{e}}$ predicted by D\&L depended on the location of the ESR radar with respect to the average location of the cusp/ cleft aurora. Near the equatorward edge of the cusp/ cleft (the location marked ESR1 in Fig. 1b of D\&L) the radar would see brief enhancements in both $N_{\mathrm{e}}$ and $T_{\mathrm{e}}$ as the open-closed boundary eroded equatorward over it (D\&L, Fig. 6a). Within the centre of the cusp/cleft band (the location marked ESR2 in D\&L's Fig. 1b), some weak structure in $N_{\mathrm{e}}$ would be seen but $T_{\mathrm{e}}$ was predicted to be almost uniformly elevated (D\&L, Fig. 6b). On the poleward edge of the cusp/cleft (the location ESR3 in D\&L's Fig. 1b), the passage of transient polewardmoving events over the ESR would be marked by clear enhancements in both $N_{\mathrm{e}}$ and $T_{\mathrm{e}}$ (D\&L, Fig. 6c). 
In Fig. 2, event $a$ causes a signature in neither $N_{\mathrm{e}}$ nor $T_{\mathrm{e}}$ but this is not surprising as the main $630 \mathrm{~nm}$ transient is not seen until it is poleward of the ESR. Events $b$ and $c$ are in the centre of the cusp/cleft region and, as predicted, events are difficult to define in the ESR measurements of $N_{\mathrm{e}}$ and $T_{\mathrm{e}}$. However, events $d, e, f$ and $g$ all show rises in both $N_{\mathrm{e}}$ and $T_{\mathrm{e}}$, as predicted by the model for near the poleward edge of the cusp/cleft. Note that exact correspondence of the timing of optical events and events in the ESR data should not be expected because of the uncertainty in the zenith angle that best corresponds to the ESR field line. The higher altitude of the $N_{\mathrm{e}}$ peak suggests the precipitation is softer than assumed in the simulations.

However there is much additional structure observed that was not predicted by the model of D\&L. For example, there are enhancements in $N_{\mathrm{e}}$ seen between events $d$ and $e$, and between events $f$ and $g$. There are also enhancements in $T_{\mathrm{e}}$ between events $a$ and $b$ and, in particular, between $f$ and $g$ (the latter is marked by the vertical arrow). There are also enhancements in $T_{\mathrm{e}}$ that can be associated with events $b$ and c. One major factor that was not included in the predictions by D\&L was structure in the electron precipitation, beyond that associated with ion flight times and time elapsed since reconnection. Another factor not included (because D\&L only modelled cases where IMF $B_{y}$ was zero) was the effect on plasma loss rates of rapid convection flow. The ion heating shown in the bottom panel of Fig. 2 reveals that flows were large and highly variable. In the next section, we consider the effects of these two additional factors.

\subsection{The origin of plasma structure in and between $630 \mathrm{~nm}$ cusp/cleft transients}

Poleward-moving $630 \mathrm{~nm}$ transients were the first putative signature of pulsed reconnection detected in the cusp/cleft ionosphere (Sandholt et al., 1992, and references therein). However, there are features of these events that are still not understood. In particular, it is not known why there are minima in luminosity between events and how events can re-brighten as they propagate (Fasel et al., 1992). Neither of these features were reproduced in the modelling by D\&L which was based on the concept that both the convection flows and the precipitation on each newly opened field line are a function of only the elapsed time since reconnection. Although this enabled simulation of poleward-moving $630 \mathrm{~nm}$ transients (D\&L, Fig. 5), these were not exactly the same as the observations. In particular, the simulated events appeared as poleward-moving ridges in the $630 \mathrm{~nm}$ intensity but did not have clear minima in luminosity between successive events. Observations, on the other hand, clearly show these minima (as, for example, in Fig. 1). The cusp ion steps reveal that the patches of newly opened flux produced by successive reconnection pulses are appended directly to each other in a contiguous fashion, as predicted by Cowley et al. (1991b). In the simulations by D\&L, these patches of newly opened magnetic flux are filled with a magnetosheath electron flux that is set by the ion flux, so as to maintain the observed quasi-neutrality in the cusp (Burch, 1985). This results in both the electron and ion precipitations in the cusp/cleft being a function of only elapsed time since reconnection and gives polewardmoving ridges in the $630 \mathrm{~nm}$ luminosity, but with no minima between events.

Therefore, one possibility is that the electron (but not the ion) precipitation is structured by a mechanism that was not included in the model. Cleft/cusp passes usually show varying degrees of structure in the electron precipitation and this becomes even more apparent poleward of the cusp, in the region classed as mantle. Corresponding structure is apparent in the ESR data shown here (Fig. 2), in particular the additional structure in the elevated electron temperatures discussed in section 4.1. The satellite observations of cusp ion steps by Lockwood et al. (1993c) showed that the largest fluxes of electron precipitation were bunched up into narrow bands near the steps. However, it is not known if this association is general for all cases. In addition, the reason for such electron precipitation structure is not understood. It may be connected to the requirement to maintain quasi-neutrality in the cusp (Burch et al., 1985). However, Lockwood and Hapgood (1997, 1998) have shown that electron observations near the magnetopause are well ordered by elapsed time since reconnection (and explained this in terms of ion flight time effects and the maintenance of quasi-neutrality by the electron gas). Similarly, Wing et al. (1996) used quasi-neutrality and the ion precipitation model of Onsager et al. (1993) to predict the electron precipitation into the ionosphere but they too did not find structure beyond that due to time elapsed since reconnection. Thus the maintenance of quasi-neutrality in the cusp is not, on its own, a cause of the electron structure we would require to explain the $630 \mathrm{~nm}$ luminosity structure.

The field-aligned currents required to transfer momentum to the ionospheric flow channels appear to influence the electron precipitation and the aurora it causes (Lockwood et al., 1993a; Milan et al., 2000). It is possible that the electron precipitation is more energetic in regions of upward current (which would be on the equatorward edge of these eastward-moving events) which increases the $557.7 \mathrm{~nm}$ and UV emission there, but could cause a minimum in the $630 \mathrm{~nm}$ emission.

The second possibility is that the $630 \mathrm{~nm}$ emission is modulated by the thermal plasma concentration of the cusp/cleft F-region ionosphere, $N_{\mathrm{e}}$. This arises because the $\mathrm{O}\left({ }^{1} \mathrm{D}\right)$ state of the atomic oxygen gas (which subsequently decays to the ground state via the emission of a $630 \mathrm{~nm}$ photon) has a low threshold energy of excitation $(1.96 \mathrm{eV})$, which is exceeded by the hot tail of the heated F-region thermal electron gas in the cusp/ cleft region (Wickwar and Kofmann, 1984; Lockwood et al., 1993a). The excitation cross-section increases steeply with electron energy, making this thermal excitation an important factor. For this mechanism, 
the number of thermal electrons of energy above the excitation threshold $(1.96 \mathrm{eV})$ will depend on both the temperature $T_{\mathrm{e}}$ and the concentration $N_{\mathrm{e}}$ of the F-region electron gas: thus the $630 \mathrm{~nm}$ volume emission rate can be modulated by variations in both $T_{\mathrm{e}}$ and $N_{\mathrm{e}}$. Structured electron precipitation, as discussed above, would be the most likely cause of the structure in $T_{\mathrm{e}}$; however, structure in $N_{\mathrm{e}}$ could also arise from other factors. In particular, the concentration of sub-auroral plasma that is convected into the cusp region (Lockwood and Carlson, 1992) may vary and/or the fast ion flows that raise the ion temperature may also cause decreases in $N_{\mathrm{e}}$ because the loss rates of the plasma are enhanced (Schunk et al., 1975). Rodger et al. (1994) suggested these velocity-dependant loss rates may be a significant factor in the cusp/cleft ionosphere. Balmforth et al. $(1998,1999)$ have modelled the effect of a transient flow channel lasting 5 minutes and found results to be consistent with EISCAT observations of a co-located plasma depletion. In this simulation, the peak F layer $N_{\mathrm{e}}$ was found to decrease by a factor of about 3 , and the height of the peak rose from about $300 \mathrm{~km}$ to $400 \mathrm{~km}$ as the bottomside F-layer was preferentially eroded.

The difference in the altitude of peak plasma concentration in Fig. 3 shows that the transient $630 \mathrm{~nm}$ event is not simply EUV-produced plasma that has been broken off from the sub-auroral ionosphere by time-varying convection, and the elevated electron temperatures show the effects of heating by soft particle precipitation in the cusp/cleft region (Whitteker, 1977; Waterman et al., 1992, 1994). There are two effects of the precipitation on the $N_{\mathrm{e}}$ profile, firstly the production of additional ionisation at F-layer heights, secondly an upward thermal expansion of the whole layer because the electron temperature is raised. Both electron and ion precipitations increase $N_{\mathrm{e}}$ (Millward et al., 1999). The profile taken between the transients $f$ and $g$ shows that $T_{\mathrm{e}}$ can be almost as high between $630 \mathrm{~nm}$ events as within them, but the key difference was that $N_{\mathrm{e}}$ was lower. Figure 1 shows that the $630 \mathrm{~nm}$ luminosity between the poleward-moving events $f$ and $g$ fell to roughly one half of the values seen within the events, this is roughly the same ratio of the peak $N_{\mathrm{e}}$ at these times, as shown in Fig. 3. This fall is consistent with that modelled by Balmforth et al. and the preferential decrease of densities in the bottomside (giving a rise in the altitude of the peak) is also as they predicted. Figure 4 shows only very slight differences in the electron temperature profile at these two times. Thus these data indicate that the minimum in $630 \mathrm{~nm}$ luminosity between the poleward-moving $630 \mathrm{~nm}$ transients $f$ and $g$ was caused by lower F-region plasma concentration, reduced by a history of fast convection of that flux tube.

\subsection{An explanation of the minima \\ between poleward-moving $630 \mathrm{~nm}$ events}

All field lines reconnected at the same point on the magnetopause would, for a given set of solar wind and
IMF conditions, evolve into the polar cap in the same way. Thus all would be subjected to the same sequence of precipitations and plasma flows and this would not result in the observed poleward-moving patches of high $N_{\mathrm{e}}$ and $630 \mathrm{~nm}$ luminosity, separated by minima. One explanation is that oscillations of the IMF $B_{y}$ component could modulate the zonal flow experienced by different field lines, as has been observed by Stauning (1994) and Stauning et al. (1994, 1995). In such cases, some newly opened field lines would suffer more loss than others. However for the data presented here, no such oscillation of the IMF was detected (see McCrea et al., this issue) and there are many other examples of poleward-moving $630 \mathrm{~nm}$ transients reported in the literature that are not accompanied by any IMF $B_{y}$ changes.

In this section, we wish to point out here the potential significance of large longitudinal extent of events produced by reconnection pulses, as discussed in Sect. 1 . Figure 7 shows the Earth's magnetosphere from out of the ecliptic plane, looking down on the Earth's north magnetic pole. The thick dashed line is the bow shock, the solid line is the non-reconnecting magnetopause and the thin dashed line is a reconnecting segment of the equatorial magnetopause. Magnetic field lines are marked with arrows and the thick arrows give the direction and speed of the motion of newly opened field lines due to the curvature ("tension") force. The IMF has negative, and roughly equal, $B_{y}$ and $B_{x}$ components (ortho-garden hose orientation) as seen during the interval of southward IMF relevant to the data presented here (McCrea et al., this issue). The figure shows a draped IMF field line, a field line that has been reconnected near noon at $A$ and one that has been reconnected away from noon on the dawn flank at $B$.

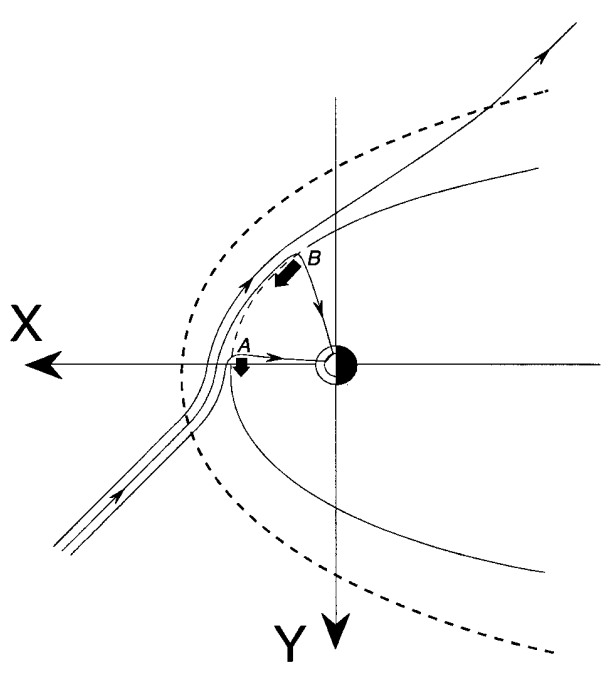

Fig. 7. Schematic of the magnetosphere, a draped interplanetary field line and two newly opened field lines, viewed from out of the ecliptic plane from above the north pole when the IMF $B_{z}, B_{y}$ and $B_{x}$ components are all negative. Compared to the field line reconnected at $A$ (near noon), that reconnected at $B$ (nearer the dawn flank) has a larger curvature of the field in the $X Y$ plane, giving a larger eastward component to the curvature force and faster eastward motion 
Inside the magnetosphere, the newly opened field lines lie approximately in their meridian planes and appear as straight lines in this perspective.

The field line reconnected at $B$ is more highly kinked in the YX plane than that reconnected at $A$. It therefore experiences a greater curvature force in the eastward direction. This will drive faster eastward flows over the magnetopause (Gosling et al., 1990) and in the ionosphere (Heelis, 1984); these will also last longer as the kink will take longer to straighten (Saunders, 1989). Thus the field line opened at $B$ will experience greater plasma loss in the F-region ionosphere than that reconnected at $A$. Furthermore, the flux of sheath particles entering on a field line opened at $B$ will initially be lower because magnetosheath plasma concentration is lower away from the nose of the magnetosphere. These differences may result in the field lines opened at $B$ entering the polar cap with considerably lower ionospheric concentrations at their feet than those that were reconnected at $A$.

The ionospheric motion of field lines opened at $A$ will turn to poleward more quickly than those opened at $B$. In addition, field lines may be opened at $A$ before they are opened at $B$ because of any propagation in the pulse of the reconnection rate away from noon, as suggested by Lockwood (1994). This effect is illustrated schematically in Fig. 8. Consider a reconnection pulse acting over a short X-line that forms near $A$ in Fig. 7 and then propagates away from noon, and towards dawn, before reconnection ceases near $B$. The top panel of Fig. 8 shows the newly opened flux in four ionospheric areas (labelled 1-4) in the northern hemisphere, produced in four intervals of time during this propagation of the active reconnection site over the equatorial magnetopause. The ionospheric projections of $A$ and $B$ in Fig. 7 are marked and the vertical line is a fixed MLT meridian with dawn towards the right and dusk to the left of each panel.

In subsequent panels, all field lines in these patches migrate eastward under the influence of the curvature force for the negative IMF $B_{y}$. Field lines in region 4 move eastward faster than those in 1 . The curvature force decays away as the newly opened field lines pass through the marked meridian and the field line motion therefore evolves towards poleward. Figure 8 shows how the field lines in region 4 progressively migrate to the equatorward edge of the whole patch of newly opened flux. The F-region plasma frozen onto field lines in 4 have moved longitudinally further and faster than the plasma on the other newly opened field lines and so will have been subjected to greater depletion by the velocity-dependent loss rates.

These longitudinal effects would therefore result in the field lines on the leading edge of a patch of poleward-moving newly opened flux having greater plasma concentrations (having originated from nearer noon and been subject to somewhat smaller east-west flows for a shorter time) than those seen on the trailing edge (having originated from away from noon and been subject to higher east-west flows for longer). The former field lines would show high $630 \mathrm{~nm}$ luminosity, the latter
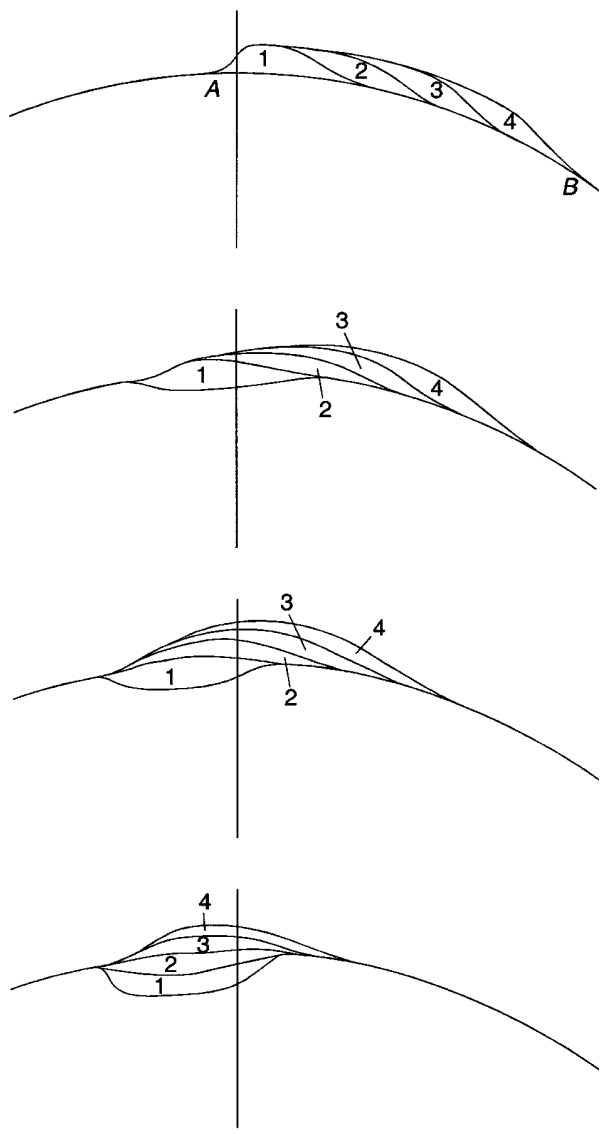

Fig. 8. Schematic of the evolution of patches of newly opened flux reconnected in one longitudinally extensive event for the same IMF orientation as in Fig. 7. Areas 1-4 are reconnected in successive time intervals by a travelling reconnection pulse that commences at $A$ and then propagates away from noon and towards dawn before reconnection ceases at $B$

lower luminosity. Appending successive events would therefore give the structure observed, with minima separating the poleward moving transients.

This gives us a plausible explanation of the structure of the $630 \mathrm{~nm}$ luminosity in poleward-moving events that agrees well with the importance of F-region plasma concentration in modulating the $630 \mathrm{~nm}$ volume emission rate, as we inferred in Sect. 4.2.

\subsection{An explanation of re-brightening of events}

Considering the role of enhanced ion flow in suppressing plasma concentrations and the $630 \mathrm{~nm}$ luminosity between events, as invoked above, it is interesting to study event $g$ in Fig. 2. Within the second brightening of this event, as seen by the MSP, the high plasma concentrations were exactly coincident with the low ion temperatures. At 06:54-55 we can identify this event, in its initial bright form, with a channel of fast eastward flow equatorward of the ESR, as seen at this time by the CUTLASS radar (Fig. 6) (see Sect. 4.5). Thus a consistent scenario for event $g$ is that it was initially enhanced in electron concentration and temperature 
(and thus $630 \mathrm{~nm}$ luminosity) by sheath electron precipitation down the newly opened field lines, but then this event faded in luminosity as the plasma concentrations within it were eroded by the fast eastward flow. Subsequently, the concentration and luminosity recovered again as the event motion turned to poleward and the ion heating decayed away. The recovery of the plasma concentrations would be caused by the cusp/cleft precipitation continuing to produce plasma after the loss rates were no longer enhanced by fast zonal flow. Thus the combined effects of enhanced plasma production, caused by soft particle precipitation, and enhanced plasma loss, caused by rapid zonal flow, can provide a coherent explanation of the re-brightening of polewardmoving $630 \mathrm{~nm}$ transients.

\subsection{Flows due to a sequence of reconnection pulses for large IMF $B_{y}$}

Cowley et al. (1991b) show schematically the evolution of a patch of newly opened flux, and of the associated flow equipotentials, following an isolated pulse of reconnection. They presented this evolution for two cases, with small and large magnitude of the IMF $B_{y}$ component. Lockwood et al. (1993b) and Lockwood (1994) generalised the sequence for small IMF $B_{y}$ to allow for a sequence of reconnection pulses that are closer in time than the duration of the effects of each. The data presented here are for large IMF $\left|B_{y}\right|$ and show 7 events in a 30-minute interval, giving a mean repeat period of about 4 minutes. Cowley and Lockwood (1992) estimate that the effects of each reconnection pulse will last for 15-20 min after the pulse has ended as the newly opened flux is appended to the tail lobe. Thus the events discussed here are forming long before the flows due to the prior event have subsided and an explanation of the observed flows requires a generalisation of the kind given by Lockwood (1994), but for large IMF $\left|\mathrm{B}_{\mathrm{y}}\right|$. This has been presented by Thorolfsson et al. (this issue) in a sequence of flow schematics that match both the motion of the transient patches of enhanced $630 \mathrm{~nm}$ emission and the observed flows (both speed and direction) seen by the CUTLASS radars. The inferred flow channels form at the equatorward edge of the cusp/cleft region and can also be seen in the inferred ion temperatures in the CUTLASS scans, as presented in this paper in Figs. 5 and 6. Events initially move eastward under the magnetic tension force and then poleward as the newly opened flux is appended to the polar cap. After event $g$, all events travel eastward through the MSP meridian equatorward of the ESR: these events evolve poleward into the polar cap at longitudes east of the ESR and thus their poleward motion is not recorded by the MSP.

By Eq. (1), the square of the vector difference between the ion flows $V$, and the neutral wind vector, $U$, is proportional to the rise of the field-parallel ion temperature $T_{\|}$above the exospheric neutral temperature. For the inferred poleward neutral wind, the eastward flow channels (as seen at 06:36 and 07:03 in
Figs. 5 and 6) are regions of high $|V-U|$ and hence $T_{\|}$. Thus equatorward of the main cusp/cleft events appear as regions of enhanced $T_{\|}$and this is consistent with the ESR data for events $a, b$ and $c$, as shown by the bottom panel in Fig. 2. The events seen late in their lifetime, and poleward of the main cusp/cleft, are moving poleward so that $|V-U|$ and hence $T_{\|}$are low. Outside the events at these latitudes, flows are zonal and equatorward, as the adiaroic polar cap boundary is expanding equatorward (as shown by Thorolfsson et al.) giving high $|V-U|$ and $T_{\|}$. Thus poleward of the main cusp/cleft, events appear as regions of low $T_{\|}$surrounded by higher values (as at 06:54 in Fig. 6). This is consistent with events $f$ and $g$ in Fig. 2. Thus the pattern of flows that is the evolving response to a series of reconnection pulses about 4 min apart, explains why events appear as regions of high ion temperature (surrounded by lower values) early in their lifetime, near the equatorward edge of the cusp/cleft; whereas later they appear as low ion temperatures (surrounded by higher values) near the poleward edge of the cusp/cleft.

\section{Conclusions}

The combined data seen in the cusp/cleft region on 16th December 1998 by the ESR, CUTLASS Finland radar and the Ny Alesund meridian scanning photometer can all be fitted into a common scenario in which patches of newly-opened flux produced by reconnection pulses migrate eastward under the prevailing IMF $B_{y}$ and then poleward under the antisunward sheath flow. Analysis of this sequence of events leads to a number of conclusions.

The volume emission rate of $630 \mathrm{~nm}$ light appears to be controlled by the concentration of the thermal Fregion ionospheric plasma, suggesting that it is excited by the hot tail of the thermal ionospheric electron gas. This concentration is eroded by rapid flows because of the velocity-dependent loss rates of F-region plasma and this effect is significant in the cusp/cleft region where ion-neutral frictional heating is high when the interplanetary magnetic field has a significant component in the $\mathrm{Y}$ direction.

Large longitudinal extents of events can explain the minima in $630 \mathrm{~nm}$ luminosity seen between the events because field lines reconnected away from noon experience larger and longer-lasting depletion by this effect. Similarly re-brightening of poleward-moving transients can be explained as arising from the competing effects of velocity-driven depletion and production by soft magnetosheath particle precipitation.

Transient events equatorward of the main cusp/cleft appear as higher parallel ion temperature as they pass over the ESR, whereas when seen later in the lifetime, poleward of the main cusp/cleft, they appear as regions of lower ion temperature surrounded by higher values. At intermediate times, in the centre of the cusp/cleft, events are preceded by rises in ion temperature but these fall as the event evolves towards poleward motion.

Rises in electron concentration and temperature inside $630 \mathrm{~nm}$ poleward-moving events, as predicted 
by Davis and Lockwood (1996), are clearly seen poleward of the main cusp/cleft, where ion temperatures are low within events and so plasma loss rates are not enhanced by fast flow with respect to the neutral gas, even if IMF $\left|B_{y}\right|$ is large. Equatorwards of the cusp/cleft, the rises in these parameters are likely to be eroded by the enhanced loss rates associated with fast zonal flow if the IMF $B_{y}$ component is large in magnitude.

Acknowledgements. The work of M.L., I.W.M. and S.E.M. is funded by the UK Particle Physics and Astronomy Research Council (PPARC). J.M. is funded by the Norwegian Research Council and A.T. by the European Commission under the Marie Curie research training grant scheme (TMR grant ERBFMBICT971917). We thank the director and staff of the EISCAT Scientific Association for the provision of the EISCAT and ESR. The CUTLASS radar system is supported by PPARC (grant no. PPA/R/R/1997/00256), UK, the Swedish Institute for Space Physics, Uppsala, and the Finnish Meteorological Institute, Helsinki. The EISCAT radars were run using an international pool of Special Programme observation time contributed by the UK, Norway, France and Sweden. The CUTLASS radars were run using French Discretionary Time on the SuperDARN network. The authors are also grateful to B. Lybekk of University of Oslo for assistance with the optical observations.

The Editor in Chief thanks a referee for his help in evaluating this paper.

\section{References}

Balmforth, H. F., R. J. Moffett, and A. S. Rodger, Modelling studies of the effects of cusp inputs on the polar ionosphere, Adv. Space Res., 22(9), 1391-1394, 1998.

Balmforth, H. F., R. J. Moffett, and A. S. Rodger, Localised structure ion the cusp and high latitude ionosphere, a modelling study, Ann. Geophys., 17, 455-462, 1999.

Burch, J. L., Quasi-neutrality in the polar cusp, Geophys. Res. Lett., 12, 469-472, 1985.

Cowley, S. W. H., and M. Lockwood, Excitation and decay of solar-wind driven flows in the magnetosphere-ionosphere system, Ann. Geophys., 10, 103-115, 1992.

Cowley, S. W. H., J. P. Morelli, and M. Lockwood, Dependence of convective flows and particle precipitation in the high-latitude dayside ionosphere on the $\mathrm{X}$ and $\mathrm{Y}$ components of the interplanetary magnetic field, J. Geophys. Res., 96, 55575564, 1991a.

Cowley, S. W. H., M. P. Freeman, M. Lockwood, and M. F. Smith, The ionospheric signature of flux transfer events, in CLUSTER - dayside polar cusp, Ed. C.I. Barron, European Space Agency Publications, Nordvijk, The Netherlands, ESA SP-330, 105-112, 1991b.

Davies, J. A., M. Lester, and I. W. McCrea, A statistical study of ion frictional heating observed by EISCAT, Ann. Geophys., 15, 1399-1411, 1997.

Davies, J. A., M. Lester, and I. W. McCrea, Solar and seasonal dependence of ion frictional heating, Ann. Geophys., 17, 682691, 1999.

Davis, C. J., and M. Lockwood, Predicted signatures of pulsed reconnection in ESR data, Ann. Geophys., 14, 1246-1256, 1996.

Escoubet, C. P., M. F. Smith, S. F. Fung, P. C. Anderson, R. A. Hoffman, E. M. Basinska, and J. M. Bosqued, Staircase ion signature in the polar cusp: a case study, Geophys. Res. Lett., 19, 1735-1738, 1992.

Fasel, G. J., J. I. Minow, R. W. Smith, C. S. Deehr, and L. C. Lee, Multiple brightenings of transient dayside auroral forms during oval expansions, Geophys. Res. Lett., 19, 2429-2432, 1992.
Fasel, G. J., Dayside poleward moving auroral forms: a statistical study, J. Geophys. Res., 100, 11 891-11 905, 1995.

Farrugia, C. J., P. E. Sandholt, W. F. Denig, and R. B. Torbert, Observation of a correspondence between poleward-moving auroral forms and stepped cusp ion precipitation, J. Geophys. Res., 103, 9309-9315, 1998.

Fedorov, A., E. Budnik, M. Novrachev, V. Romanov, P. Song, J.-A. Savaud, Plasma characteristics near the exterior cusp under different orientations of the interplanetary magnetic field, Czech J. Phys., 49, 711-732, 1999.

Gosling, J. T., M. F. Thomsen, S. J. Bame, R. C. Elphic, and C. T. Russell, Plasma flow reversals at the dayside magnetopause and the origin of asymmetric polar cap convection, J. Geophys. Res., 95, 8073-8084, 1990.

Heelis, R. A., The effects of interplanetary magnetic field orientation on dayside high-latitude convection, J. Geophys. Res., 89, 2873-2880, 1984.

Jenkins, B., R. J. Moffett, J. A. Davies, and M. Lester, Nightside ion-neutral frictional heating: atomic and molecular ion temperature anisotropy and ion composition changes, J. Atmos. sol-terr. Phys., 59, 1329-1343, 1997.

Karlson, K. A., M. Øieroset, J. Moen, and P. E. Sandholt, A statistical study of flux transfer event signatures in the dayside aurora: the IMF $\mathrm{B}_{\mathrm{y}}$-related postnoon-prenoon asymmetry, J. Geophys. Res., 101, 59-68, 1996.

Lathuillere, C., D. Hubert, C. La Hoz, and W. Kofman, Evidence of anisotropic temperatures of molecular ions in the auroral ionsophere, Geophys. Res. Lett., 18, 163-166, 1991.

Lockwood, M., Ionospheric signatures of pulsed magnetopause reconnection, in Physical signatures of magnetopause boundary layer Processes, Eds. J.A. Holtet, A. Egeland, NATO ASI Ser. C, Kluwer, 425, 229-243, 1994.

Lockwood, M., Energy and pitch angle dispersions of LLBL/cusp ions seen at middle altitudes: predictions by the open magnetosphere model, Ann. Geophys., 15, 1501-1511, 1997.

Lockwood, M., and H. C. Jr.Carlson, Production of polar cap electron density patches by transient magnetopause reconnection, Geophys. Res. Lett., 19, 1731-1734, 1992.

Lockwood, M., and C. J. Davis, On the longitudinal extent of magnetopause reconnection bursts, Ann. Geophys., 14, 865-878, 1996.

Lockwood, M., and M. A. Hapgood, How the magnetopause transition parameter works, Geophys. Res. Lett., 24, 373-376, 1997.

Lockwood, M., and M. A. Hapgood, On the Cause of a magnetospheric flux transfer event, Geophys. Res., 103, 26 453-26 478, 1998.

Lockwood, M., and J. Moen, Reconfiguration and closure of lobe flux by reconnection during northward IMF: evidence for signatures in cusp/cleft auroral emissions, Ann. Geophys., 17, 996-1011, 1999.

Lockwood, M., and M. F. Smith, The variation of reconnection rate at the dayside magnetopause and cusp ion precipitation, J. Geophys. Res., 97, 14 841-14 847, 1992.

Lockwood, M., and M. F. Smith, Low- and mid-altitude cusp particle signatures for general magnetopause reconnection rate variations, I, theory, J. Geophys. Res., 99, 8531-8555, 1994.

Lockwood, M., and M. N. Wild, On the quasi-periodic nature of magnetopause flux transfer events, J. Geophys. Res., 98, 59355940, 1993.

Lockwood, M., P. E. Sandholt, and S. W. H. Cowley, Dayside auroral activity and momentum transfer from the solar wind, Geophys. Res. Lett., 16, 33-36, 1989a.

Lockwood, M., P. E. Sandholt, S. W. H. Cowley, and T. Oguti, Interplanetary magnetic field control of dayside auroral activity and the transfer of momentum across the dayside magnetopause, Planet. Space Sci., 37, 1347-1365, 1989b.

Lockwood, M., S. W. H. Cowley, P. E. Sandholt, and R. P. Lepping, The ionospheric signatures of flux transfer events and solar wind dynamic pressure changes, J. Geophys. Res., 95, 17 113$17136,1990$. 
Lockwood, M., H. C. Carlson, and P. E. Sandholt, The implications of the altitude of transient $630 \mathrm{~nm}$ dayside auroral emissions, J. Geophys. Res., 98, 15 571-15 587, 1993a.

Lockwood, M., J. Moen, S. W. H. Cowley, A. D. Farmer, U. P. Løvhaug, H. Lühr, and V. N. Davda, Variability of dayside convection and motions of the cusp/cleft aurora, Geophys. Res. Lett., 20, 1011-1014, 1993b.

Lockwood, M., W. F. Denig, A. D. Farmer, V. N. Davda, S. W. H. Cowley, and H. Lühr, Ionospheric signatures of pulsed magnetic reconnection at the Earth's magnetopause, Nature, 361 (6411), 424-428, 1993c.

Lockwood, M., I. W. McCrea, G. H. Millward, R. J. Moffett, and H. Rishbeth, EISCAT observations of ion composition and temperature anisotropy in the high-latitude F-region, J. Atmos. Terr. Phys., 55, 895-906, 1993d.

Lockwood, M., S. W. H. Cowley, P. E. Sandholt, and U. P. Løvhaug, Causes of plasma flow bursts and dayside auroral transients: an evaluation of two models invoking reconnection pulses and changes in the $\mathrm{Y}$-component of the magnetosheath field, J. Geophys. Res., 100, 7613-7626, 1995a.

Lockwood, M., S. W. H. Cowley, M. F. Smith, R. P. Rijnbeek, and R. C. Elphic, The contribution of flux transfer events to convection, Geophys. Res. Lett., 22, 1185-1188, 1995b.

Lockwood, M., C. J. Davis, T. G. Onsager, and J. A. Scudder, Modelling signatures of pulsed magnetopause reconnection in cusp ion dispersion signatures seen at middle altitudes, Geophys. Res. Lett., 25, 591-594, 1998.

McCrea, I. W., and M. Lockwood, Incoherent scatter radars, in Ground-based observations in support of the Cluster mission, Eds. M. Lockwood, M. N. Wild, H. J. Opgenoorth, ESA Publications, ESTEC, Nordvijk, The Netherlands, ESA SP-1198, 239266, 1997.

McCrea, I. W., M. Lester, T. R. Robinson, N. M. Wade, and T. B. Jones, On the identification and occurrence of ion frictional heating events in the high-latitude ionosphere, J. Atmos. Terr. Phys., 53, 587-597, 1991.

McCrea, I. W., M. Lester, T. R. Robinson, J.-P. St.-Maurice, N. M. Wade, and T. B. Jones, Derivation of the ion temperature partition coefficient $B$ from the study of ion frictional heating events, J. Geophys. Res., 98, 15 701-15 715, 1993.

McCrea, I. W., M. Lockwood, J. Moen, F. Pitout, P. Eglitis, and A. D. Aylward, ESR and EISCAT observations of the response of the cusp and cleft to IMF orientation changes, Ann. Geophys., (this issue), 2000.

Milan, S. E., M Lester, S. W. H. Cowley, J. Moen, P. E Sandholt, and C. J. Owen, Meridian-scanning photometer, coherent HF radar, and magnetometer, observations of the cusp: a case study, Ann. Geophy., 17, 159-172, 1999.

Milan, S. E., M. Lester, S. W. H. Cowley, and M. Brittnacher, Convection and auroral response to a southward turning of the IMF, Polar UVI, CUTLASS and IMAGE signatures of transient magnetic transfer at the magnetopause, J. Geophys. Res., 105, 15 741-15 755, 2000.

Millward, G. H., R. J. Moffett, H. F. Balmforth, and A. S. Rodger, Modelling the ionospheric effects of ion and electron precipitation in the cusp, J. Geophys. Res., 104, 24 603-24 612, 1999

Moen, J., P. E. Sandholt, M. Lockwood, W. F. Denig, U. P. Løvhaug, B. Lybekk, A. Egeland, D. Opsvik, and E. FriisChristensen, Events of enhanced convection and related dayside auroral activity, J. Geophys. Res., 100, 23 917-23 934, 1995.

Moen, J., M. Lockwood, P. E. Sandholt, U. P. Lovhaug, W. F. Denig, A. P. van Eyken, and A. Egeland, Variability of dayside high-latitude convection associated with a sequence of auroral transients, J. Atmos. Terr. Phys., 58, 85-96, 1996a.

Moen, J., D. Evans, H. C. Carlson, and M. Lockwood, Dayside moving auroral transients related to LLBL dynamics, Geophys. Res. Lett., 23, 3247-3250, 1996b

Newell, P. T., and C.-I. Meng, Dipole tilt effects on the latitude of the cusp/low-latitude boundary layer, J. Geophys. Res., 94, 6949,1989
Newell, P. T., and D. G. Sibeck, Upper limits on the contribution of flux transfer events to ionospheric convection, Geophys. Res. Lett., 20, 2829-2832, 1993a.

Newell, P. N., and D. G. Sibeck, $B_{y}$ fluctuations in the magnetosheath and azimuthal flow velocity transients in the dayside ionosphere, Geophys. Res. Lett., 20, 1719-1723, 1993b.

Onsager, T. G., C. A. Kletzing, J. B. Austin, and H. MacKiernan, Model of magnetosheath plasma in the magnetosphere: Cusp and mantle particles at low-altitudes, Geophys. Res. Lett., 20, 479-482, 1993.

Pinnock, M., A. S. Rodger, J. R. Dudeney, K. B. Baker, P. T. Newell, R. A. Greenwald, and M. E. Greenspan, Observations of an enhanced convection channel in the cusp ionosphere, J. Geophys. Res., 98, 3767-3776, 1993.

Pinnock, M., A. S. Rodger, J. R. Dudeney, F. Rich, and K. B. Baker, High spatial and temporal resolution observations of the ionospheric cusp, Ann. Geophys., 13, 919-925, 1995.

Provan, G., and T. K. Yeoman, Statistical observations of the MLT, latitude and size of pulsed ionospheric flows with CUTLASS Finland radar, Ann. Geophys., 17, 855-867, 1999.

Provan, G., T. K. Yeoman, and S. E. Milan, CUTLASS Finland radar observations of the ionospheric signatures of flux transfer events and resulting plasma flows, Ann. Geophys., 16, 1411-1422, 1998.

Provan, G., T. K. Yeoman, and S. W. H. Cowley, The influence of the IMF $\mathrm{B}_{\mathrm{y}}$ component on the location of pulsed ionospheric flows in the dayside ionosphere observed by HF radars, Geophys. Res. Lett., 26, 521-5124, 1999.

Rodger, A. S., M. Pinnock, J. R. Dudeney, K. B. Baker, and R. A. Greenwald, A new mechanism for polar patch formation, J. Geophys. Res., 99, 6425-6436, 1994.

Ruohoniemi, J. M., R. A. Greenwald, K. B. Baker, J.-P. Villain, C. Hanuise, and J. D. Kelley, Mapping high latitude plasma convection with coherent HF radars, J. Geophys. Res., 94, 13 463-13 477, 1989.

Sandholt, P. E., M. Lockwood, W. F. Denig, R. C. Elphic, and S. Leontjev, Dynamical auroral structure in the vicinity of the polar cusp: multipoint observations during southward and northward IMF, Ann. Geophys., 10, 483-497, 1992.

Saunders, M. A., The origin of cusp Birkeland currents, Geophys. Res. Lett., 16, 151-154, 1989.

Schunk, R. W., and J. J. Sojka, Ionospheric hot spot at high latitudes, Geophys. Res. Lett., 9, 1045-1048, 1982.

Schunk, R. W., W. J. Raitt, and P. M. Banks, Effect of electric fields on the daytime high latitude E- and F-regions, J. Geophys. Res., 80, 3121-3130, 1975.

Sedgemore-Schulthess, K. J. F., M. Lockwood, T. S. Trondsen, B. S. Lanchester, M. H. Rees, D. Lorentzen, and J. Moen, EISCAT Svalbard radar and optical observations of transient fieldaligned currents and aurora in the dayside cusp, J. Geophys. Res., 104, 24 613-24 624, 1999.

Stauning, P., Coupling of IMF $\mathrm{B}_{\mathrm{y}}$ variations into the polar ionospheres through interplanetary field-aligned currents, J. Geophys. Res., 99, 17 309-17 322, 1994.

Stauning, P., E. Friis-Christensen, O. Rasmussen, and S. Vennerstrøm, Progressing polar convection disturbances: signature of an open magnetosphere, J. Geophys. Res., 99, 11 303-11 317, 1994.

Stauning, P., C. R. Clauer, T. J. Rosenberg, R. Friis-Christensen, and R. Sitar, Observations of solar-wind-driven progression of interplanetary magnetic field $\mathrm{B}_{\mathrm{y}}$-related dayside ionospheric disturbances, J. Geophys. Res., 100, 7567-7585, 1995.

Thorolfsson, A., J. C. Cerisier, M. Lockwood, P. E. Sandholt, C. Senior, and M. Lester, Simultaneous radar and optical signatures of poleward-moving auroral forms, Ann. Geophys., (this issue), 2000.

Watermann, J., O. de la Beaujardiere, and P. T. Newell, Incoherent scatter radar observations of ionospheric signatures of cusp-like electron precipitation, J. Geomag. Geoelect., 44, 1195-1206, 1992.

Watermann, J., O. de la Beujardiére, D. Lummerzheim, J. Woch, P. T. Newell, T. A. Potemra, F. J. Rich, and M. Shapshak, The 
dynamic cusp at low altitudes: a case study utilizing Viking, DMSP-D7, and Sondrestrom incoherent scatter radar observations, Ann. Geophys., 12, 1114-1157, 1994.

Whitteker, J. H., The transient response of the topside ionosphere to precipitation, Planet. Space Sci., 25, 773-768, 1977.

Wickwar, V. B., and W. Kofman, Dayside auroras at very high latitudes: the importance of thermal excitation, Geophys. Res. Lett., 11, 923-926, 1984.
Wing, S., P. T. Newell, and T. G. Onsager, Modelling the entry of the magnetosheath electrons into the dayside ionosphere, J. Geophys. Res., 101, 13 155-13 168, 1996.

Yeoman, T. K., M. Lester, S. W. H. Cowley, S. E. Milan, J. Moen, and P. E. Sandholt, Simultaneous observations of the cusp in optical, DMSP and HF radar data, Geophys. Res. Lett., 24, 2251-2254, 1997. 